\title{
Review of Seismic Assessment for High Rise Building Isolated by Dilatation to Minimize Irregularity
}

\author{
Muhammad Aji Fajari $^{1 *}$ and Ririt Aprilin Sumarsono ${ }^{1}$ \\ ${ }^{1}$ Department of Civil Engineering, Universitas Negeri Jakarta, Jalan Rawamangun Muka, 13220 \\ Jakarta, Indonesia
}

\begin{abstract}
Noticeably, the design of today's building particularly high rise building and skyscraper show irregularity in both horizontal and vertical direction which is dangerous for each element inside the building. Handily, certain disjoint can be applied to the building to minimize the irregularity for better desired behaviour. Dilatation is a well-known method together with several other methods are introduced and implemented for gaining principal of simple regular building. Double column and cantilever beam method are two of them which are excellent to divide the building into several regular buildings after they are applied. The double column is found out to perform better on dilatation direction application at the weak axis of the building. Moreover, accurate review of double column distance will solve the load transfer discontinuity so that better behaviour and performance can be satisfied. Hereinafter, the cantilever beam conducts perfectly when the shear wall is sufficiently installed and the cantilever beam span is contently fulfilled. Shear wall remarkably contributes to enhancing the behaviour and performance of the structure as the shear wall placement is proper to absorb seismic lateral force. Recommendation of both systems can be well performed once the column distance, cantilever span, and shear wall installation are strongly taken into consideration.
\end{abstract}

Keywords: Irregularity, dilatation, double column, cantilever beam, performance of structure

\section{Introduction}

Fatalities due to the earthquake have arisen the awareness of structural designer to gain safer structure after the attack of the earthquake. It cannot be neglected that building structure plays an important role to withstand under seismic load. Better configuration of building plan produces a better response to the overall building beside installing seismic resistant components inside. Regularity issue of the building whether in horizontal, vertical, or both directions has been clearly categorized in seismic design codes. Vertical and horizontal irregularity in the building must be considered for certain seismic design category [1].

\footnotetext{
*Corresponding author: ajfajari182@gmail.com
} 
One of the main goals in seismic design is improving the understanding of earthquake and its effect [2]. Widely, the improvements cover the earthquake monitoring, understanding of earthquake occurrence, fundamental knowledge of earthquake effects, and application seismic design structure. Grounded from those, the economic cost can be decreased as well as eliminating crucial destruction on building structure under the earthquake.

Several devastating earthquakes, particularly the 1989 Loma Prieta and 1994 Northridge earthquakes in California, the 1995 Kobe earthquake in Japan, 2009 L'Aquilla and 2012 Emilia Romagna in Italy and 2011 Lorca earthquake in Spain have caused significant damage to the buildings [3]. Some lessons from those earthquakes have a significant impact on the technology for resisting the seismic load such shear wall, seismic isolator, dampers, and so forth to fulfill safety requirements. Nowadays the base isolation techniques represent an interesting design strategy for decoupling the structure from the damaging effects due to ground accelerations in case of seismic events [4].

Specifically for shear wall system, it is selected due to its easiness and low cost application together with the moment resisting frame compare to another system. The linear sway of the moment frame, combined with the parabolic sway of the shear wall, resulted in enhanced stiffness because the wall is restrained by the frame at the upper levels while at the lower levels the shear wall is restrained by the frame [5].

It is a well-known fact that buildings where the primary or only the lateral forceresisting mechanism, consists of walls are frequently called "shear wall" buildings [6]. Confidently, installation of the shear wall needs further consideration to see its necessity and effectiveness. Besides, the configuration of the building must be appropriately pointed out in order to place the shear wall efficiently. Building with irregularity will be recommended for seismic resistant installation; prominently shear wall can increase the stiffness of the building so that the response of the building under the earthquake can be well improved. In contrary, the choice of fixing the structural response of the irregular building can be gone through dilatation as seen in Fig. 1. Creating separation on the building can be acquired by using double column, cantilever beam, console beam, and Gerber beam.

1.

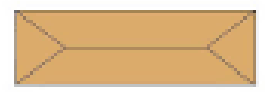

2.

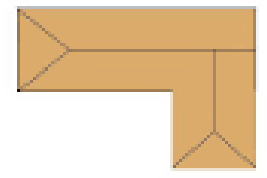

3.

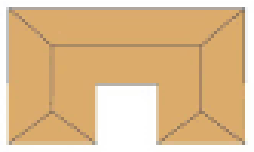

1.

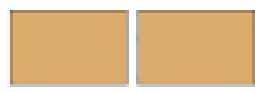

2.

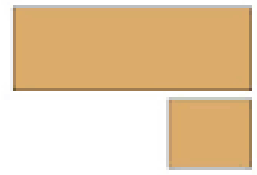

3.

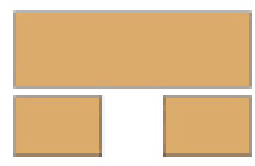

Fig. 1. Dilatation concept

Harnessing each of the systems will result in a different response of the building structure. The double column is practically easy to be applied if the requirements of building floor plan consumption can be adjusted due to the extra column built near the intersection. The same fact also is met once the cantilever beam is taken into a choice for dilatation. The main problem of flexure of long cantilever beam might create another problem so that it is suggested to apply only $1 / 3$ maximum length for the cantilever beam span. Otherwise, beam modification through console and Gerber beam will result in no 
modification in the building floor plan. Gerber beam has a tendency of experiencing more failure as the lateral load rises.

\subsection{Research coverage}

In this paper, simulation and analysis exploit Heliconia Apartment Tower of Bassura City, which is a $U$ plan symmetric building, which consists of 25 stories as seen in Fig. 2. The arrangement of the shear wall is also perfectly symmetric in both $X$ and $Y$ directions. Extra walls are installed in the 2-basement floor around the perimeter of the building recognized as diaphragm wall. Basically, the diaphragm wall is functioned to resist the soil and water pressure in the basement floor.

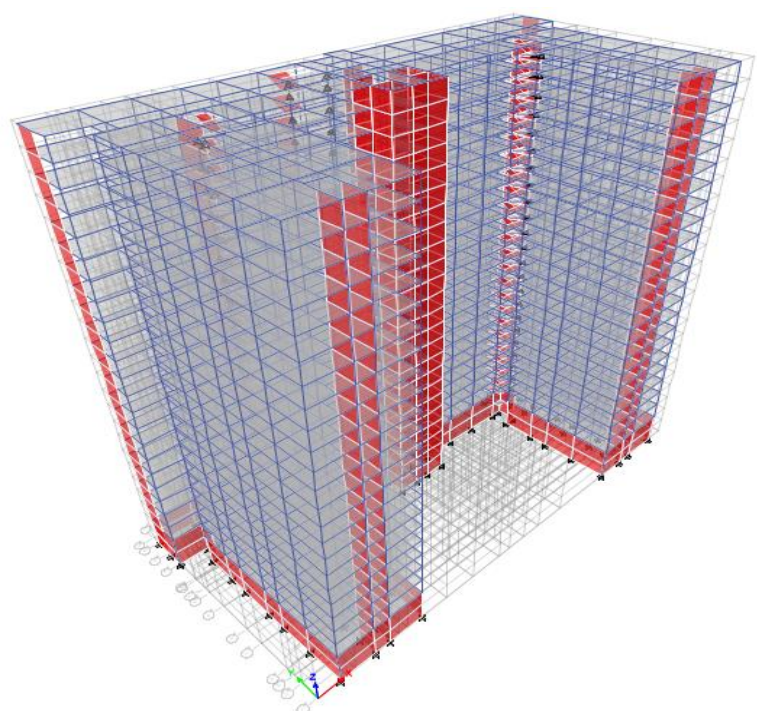

Fig. 2. Isometric of U-shaped plan building

Several intersections are noticed in this building so that the dilatation option will be done in both $X$ and $Y$ directions through the application of a double column and a cantilever beam. Refer to Fig. 3, four variations will be harnessed in order to see the specific different response of applying double column and a cantilever beam. M1 and M2 will be intersected using double column and cantilever beam in the $X$ direction, whilst M3 and M4 in $Y$ direction. 
Dilatation in $X$ direction
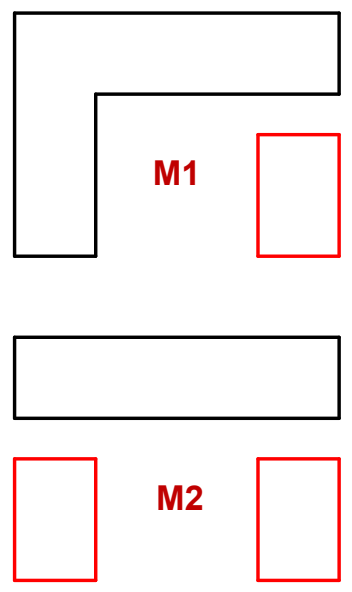
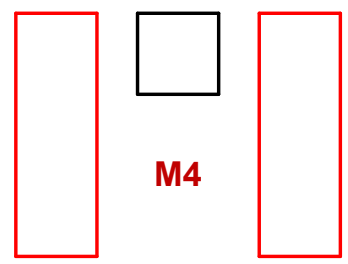

Fig. 3. Arrangement of dilatation

Structures should have the ductility necessary for bearing force of an earthquake. Considering the fact that, in structures, beam failure mechanisms provide more ductility than the column failure mechanisms and the impact of beam ductility is more significant than that of column [7]. Under the condition of strong column weak beam design, where the beam is well connected to the column, the plastic hinge location occurs near the column location. The ductility behaviour of the cantilever beam will not be the same as the conventional beam which can be predicted worse especially when the concentrated load is higher at the tip of the cantilever beam.

\subsection{Research limitation}

Noting that this building has no typical floor height, the first limitation is made to be typical floor into $2.8 \mathrm{~m}$ high. Due to it, vertical irregularity of this building is automatically disappeared. A Clear indication of horizontal irregularity of the building plan due to re-entrant corner is analyzed to $48 \%$ in the $X$ direction and $63 \%$ in the $Y$ direction.

Double column system places the distance of $3 \mathrm{~m}$ and 4-5 $\mathrm{m}$ between them. Previously, shorter distance has been proven to result in a better response compared to existing building. The size of the extra column is completely the same as the existing column in the building. Otherwise, the cantilever beam is installed for half distance of the beam which is in the location of the dilatation. All the cantilever beams applied reach more than $1.5 \mathrm{~m}$ long which can be predicted to provide worse response than the existing building.

Modelization and analysis for all the models utilize ETABS v.13 with the dynamic linear analysis response spectrum considered. Discussions will be a focus on the first mode of the building response only with the most critical results among 18 load combinations. It is strongly noted that all the models which are separated due to dilatation will still be run under one file so that the separated building section will still be considered as one building. Fig. 4 illustrates the configuration of the double column 
and cantilever beam placement of the building which result in separation in the certain intersection.

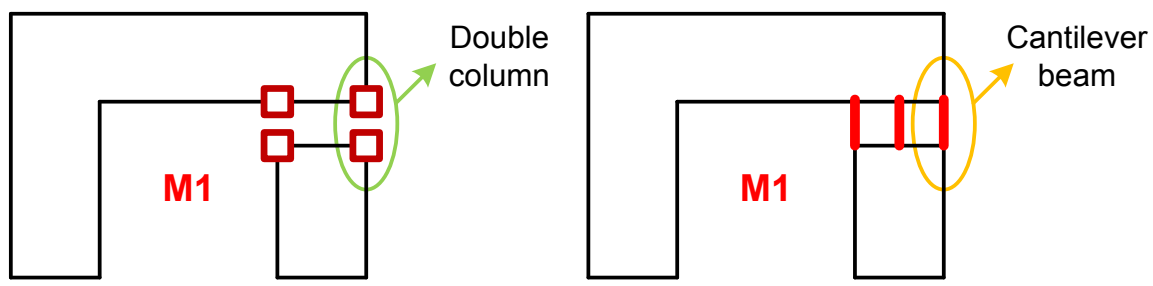

Fig. 4. Double column and cantilever beam placement

For the simulation needs, the cantilever is modeled by freeing all the restraint in one end of the beam. Both translation and rotation are released in $X, Y$, and $Z$ direction. Fixed-free end of cantilever beam has the notion of maximum bending effect to a certain limit. Adoption of the cantilever beam to separate the building under the earthquake will be discussed in this paper.

\section{Structural parameters}

As some limitations enacted, the use of the member properties will also be restricted into typical dimension and properties of the member structure to convince the absence of vertical irregularity. Further, the linear dynamic analysis response spectrum is selected to see the structural behaviour of the building with dilatation. Some data input will be obviously seen in the following subchapter.

\subsection{Member properties}

The dimension of the column is uniform from the base to the top floor as informed in Table 1 as well as the material property of the column. The same evidence is shown for the shear wall and beam dimension and properties. The difference takes place for the slab dimension in typical functional floor and basement floor where basement floor using thicker dimension which is $200 \mathrm{~mm}$.

Table 1. Properties and dimension of the structural member

\begin{tabular}{|c|c|c|c|}
\hline No. & $\begin{array}{c}\text { Structural } \\
\text { member }\end{array}$ & $\begin{array}{c}\text { Dimension } \\
(\mathrm{mm})\end{array}$ & $\begin{array}{c}\text { Material properties } \\
(\mathrm{MPa})\end{array}$ \\
\hline 1 & Column & K1H-1H -- 450×1000 & 44.13 \\
\hline 2 & Beam & G34A-1 -- 300×450 & 34.23 \\
\hline 3 & Slab & 130 & 34.23 \\
& & 200 & 34.23 \\
\hline 4 & Wall & W1H-1-350 & 44.13 \\
\hline
\end{tabular}

\subsection{Response spectra}

Elastic response spectrum represents the maximum response (over time) of a linear elastic SDF system versus its natural period (or frequency) when excited by a ground acceleration time history [8]. For each structure, we can calculate the absolute maximum value of the response of interest from the corresponding time history. In 
earthquake response calculations, the sign of response is often not considered [9]. Project site of this building denotes the following response spectrum as served in Fig. 5.

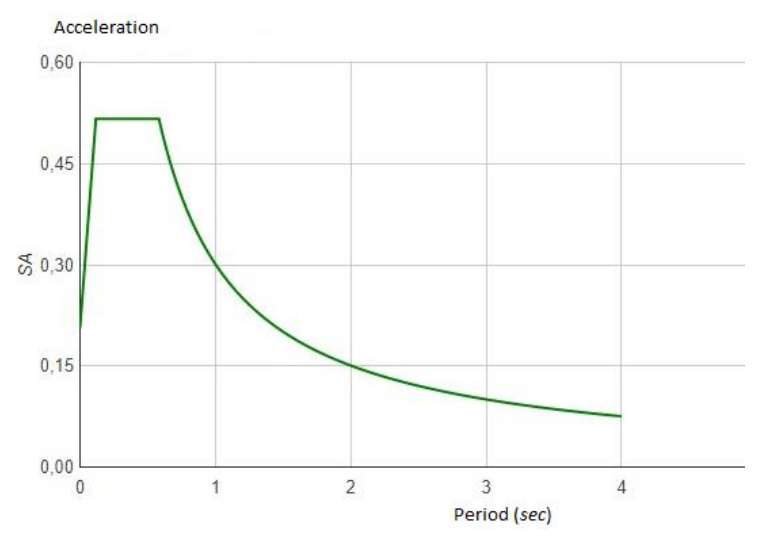

Fig. 4. Response spectrum curve

Site investigation for the soil type has generated the value of $S_{D S}$ and $S_{D 1} 0.516 g$ and $0.301 g$ respectively. In average, the soil classification of the project site can be summarized as hard soil which led to site class $C$ specification. Site characterization schemes that have been used to represent site condition include averaged shear wave velocity, surface geology, and geotechnical data [8].

\section{Analysis and results}

This section will discuss the analysis adjustment during ETABS modelization and running analysis to be further checked and criticized regarding its results. As much as 16 models are developed in this paper were two main groups of the double column (DC) and cantilever beam (Ca) model with the shear wall (SW) and non-shear wall (NSW) installation. The existing (E) building is developed as the comparison to other modified models due to dilatation application (M1 to M4). Suggestion and recommendation of the dilatation assembly based on some parameter behaviour will be intensely explained.

\subsection{Load case}

Primarily, the structure is designed to resist dead load and live load. The presence of a live load in terms of dynamic load such as earthquake, wind, and water has directed to specific load combination due to them. Specifically for earthquake load, it has to be implemented in both perpendicular directions ( $\mathrm{X}$ and $\mathrm{Y}$ ) which composition $100 \%$ in one direction and 30 $\%$ in another direction [1]. Load combinations used in this paper can be derived from the following criteria:

$$
\begin{gathered}
1.4 D L \\
1.2 D L+1.6 L L \\
1.2 D L+1.0 L L \pm 0.3\left(\rho Q_{E X}+0.2 S_{D S} D L\right) \pm 1.0\left(\rho Q_{E Y}+0.2 S_{D S} D L\right) \\
1.2 D L+1.0 L L \pm 1.0\left(\rho Q_{E X}+0.2 S_{D S} D L\right) \pm 0.3\left(\rho \mathrm{Q}_{E Y}+0.2 S_{D S} D L\right) \\
0.9 D L \pm 0.3\left(\rho Q_{E X}-0.2 S_{D S} D L\right) \pm 1.0\left(\rho Q_{E Y}-0.2 S_{D S} D L\right) \\
0.9 D L \pm 1.0\left(\rho Q_{E X}-0.2 S_{D S} D L\right) \pm 0.3\left(\rho Q_{E Y}-0.2 S_{D S} D L\right)
\end{gathered}
$$


Acknowledging the building function as a residential building, risk category under the earthquake can be grouped as category I or II which importance factor equals 1 . The occupancy importance factor enters in the base shear calculation and is influential in determining the magnitude of the base shear and earthquake design lateral forces applied to the structure [10]. During dynamic analysis, viscous elastic damping ratio of $5 \%$ is needed to be set in advance.

\subsection{Frequency of structure}

Simply, the frequency is the inverse of the period which shows a number of a cycle per second. The higher period will result in lower frequency and vice versa. Fundamental period of a structure can be approached using the following equation from [1]:

$$
T=0.1 N
$$

Noting that $\mathrm{N}$ equals to a number of stories, the fundamental period of the building results in 2.5 second and the frequency equivalent to 0.4 cycles per second. Based on ETABS simulation and analysis, the existing building produces period and frequency of 0.248 seconds and 4.026 cycles per second (see Table 2 ), in such a way the modelization process can be summarized accurately.

Table 2. Period and frequency

\begin{tabular}{|c|c|c|c|c|c|c|c|}
\hline \multicolumn{2}{|c|}{ Model } & \multirow{2}{*}{$\begin{array}{c}\begin{array}{c}\text { Period } \\
\text { (sec) }\end{array} \\
0.248 \\
\end{array}$} & \multirow{2}{*}{$\begin{array}{c}\begin{array}{c}\text { Frequency } \\
\text { (cycle/sec) }\end{array} \\
4.026 \\
\end{array}$} & \multicolumn{2}{|c|}{ Model } & \multirow{2}{*}{$\begin{array}{c}\begin{array}{c}\text { Period } \\
\text { (sec) }\end{array} \\
0.349 \\
\end{array}$} & \multirow{2}{*}{$\begin{array}{c}\begin{array}{c}\text { Frequency } \\
\text { (cycle/sec) }\end{array} \\
2.863 \\
\end{array}$} \\
\hline Existing & E-SW & & & Existing & E-NSW & & \\
\hline \multirow{4}{*}{$\begin{array}{l}\text { Double } \\
\text { Column } \\
\text { (DC) }\end{array}$} & SW-M1 & 2.170 & 0.461 & \multirow{4}{*}{$\begin{array}{c}\text { Double } \\
\text { Column } \\
\text { (DC) }\end{array}$} & NSW-M1 & 2.154 & 0.464 \\
\hline & SW-M2 & 2.205 & 0.453 & & NSW-M2 & 2.190 & 0.457 \\
\hline & SW-M3 & 1.204 & 0.831 & & NSW-M3 & 1.025 & 0.976 \\
\hline & SW-M4 & 1.220 & 0.820 & & NSW-M4 & 1.039 & 0.963 \\
\hline \multirow{4}{*}{$\begin{array}{c}\text { Cantilever } \\
\text { Beam } \\
(\mathrm{Ca})\end{array}$} & SW-M1 & 0.248 & 4.025 & \multirow{4}{*}{$\begin{array}{c}\text { Cantilever } \\
\text { Beam } \\
(\mathrm{Ca})\end{array}$} & NSW-M1 & 0.349 & 2.863 \\
\hline & SW-M2 & 0.248 & 4.025 & & NSW-M2 & 0.349 & 2.862 \\
\hline & SW-M3 & 0.248 & 4.026 & & NSW-M3 & 0.349 & 2.863 \\
\hline & SW-M4 & 0.248 & 4.026 & & NSW-M4 & 0.349 & 2.863 \\
\hline
\end{tabular}

From table 2, the frequency of SW-DC is about 8 times higher than SW-Ca model; otherwise, NSW-DC is about 5 times higher than NSW-Ca. Focusing on the period of existing building, shear wall installation will give a better response since completing one cycle takes shorter time which causes more cycles completed per second. DC indicates smaller frequency than $\mathrm{Ca}$ with or without a shear wall, analogously for the DC-SW to CASW. Clear separation of the DC model causes the load transfer discontinuity so that the behaviour is worse than $\mathrm{Ca}$ model even though the cantilever span reaches more than one third of the total length.

Disjointing the building in the $X$ direction as M1 and M2 applied provides smaller frequency than $Y$ direction as shown for M3 and M4 particularly for the DC system. Cantilever beam application in all direction to separate the building does not give a significant change in the period as well as frequency. Shortly, Ca model behaves mostly the same as the existing building in terms of period and frequency.

\subsection{Base shear}

Base shear must be calculated based on both orthogonal-horizontal directions using the fundamental period of the structure [1]. In general, greater base shear is obtained for $\mathrm{X}$ direction than $\mathrm{Y}$ direction which denotes the strong axis of the building. All DC-SW, Ca- 
SW, and DC-NSW show larger base shear value in $X$ direction except Ca-NSW model. Referring to Table 3, the shear wall contribution for both DC and Ca system due to seismic load can be well occupied even if the separation is adapted to the building.

Surprisingly, the elimination of shear wall in $\mathrm{Ca}$ model induces different base shear value between $\mathrm{DC}$ and $\mathrm{Ca}$ which conclude the change of building strong axis. As mentioned before, DC faced the discontinuity load transfer which causes worse performance in period and frequency. Base shear $X$ value in Ca-NSW model is half smaller than base shear $Y$, which is contrary to the DC-NSW results. As the beam cut and transform into cantilever by free-restraining one-end support, the higher seismic contribution shifts to the weak direction.

Table 3. Base Shear

\begin{tabular}{|c|c|c|c|c|c|}
\hline \multicolumn{3}{|c|}{ Shear Wall Model } & \multicolumn{3}{c|}{ Non-Shear Wall Model } \\
\hline Variation & $\begin{array}{c}\text { Base Shear } X \\
(\mathrm{kN})\end{array}$ & $\begin{array}{c}\text { Base Shear } Y \\
(\mathrm{kN})\end{array}$ & Variation & $\begin{array}{c}\text { Base Shear } X \\
(\mathrm{kN})\end{array}$ & $\begin{array}{c}\text { Base Shear } Y \\
(\mathrm{kN})\end{array}$ \\
\hline E-SW & 51037.4 & 3868.7 & E-NSW & 52368.6 & 46949 \\
\hline DC-SW-M1 & 32035.4 & 8692.4 & DC-NSW-M1 & 31234.6 & 9459.31 \\
\hline DC-SW-M2 & 23489.5 & 10174.1 & DC-NSW-M2 & 22618.3 & 9254.91 \\
\hline DC-SW-M3 & 30740.4 & 18429.2 & DC-NSW-M3 & 31636.9 & 13345.2 \\
\hline DC-SW-M4 & 11996.2 & 16973.5 & DC-NSW-M4 & 14499 & 14644.8 \\
\hline Ca-SW-M1 & 84237 & 8927.1 & Ca-NSW-M1 & 498103 & 1027219 \\
\hline Ca-SW-M2 & 84703.9 & 9030.5 & Ca-NSW-M2 & 497993 & 1027247 \\
\hline Ca-SW-M3 & 84235.6 & 8927.6 & Ca-NSW-M3 & 498045 & 1027245 \\
\hline Ca-SW-M4 & 84235.6 & 8927.6 & Ca-NSW-M4 & 498077 & 1027248 \\
\hline
\end{tabular}

In detail, splitting the building in $X$ and $Y$ direction delivers the significant result of base shear for DC either SW or NSW. Conversely, the Ca model does not show the same trend as DC due to constant base shear value resulted. Distinctly, the absence of shear wall in the $\mathrm{Ca}$ model has manipulated as if the strong axis of the building is moved to the $Y$-axis.

Relating the base shear and displacement in the strong axis direction of the building ( $X$ direction) delivers almost constant base shear and displacement value from Ca-SW-M1 to CA-SW-M4 like Ca-NSW-M1 to Ca-NSW-M4 as referred to Fig. 5. The location of the dilatation of $\mathrm{Ca}$ model has no impact in the value of base shear and displacement. As the cantilever is simply divided into two from the total beam span, the significant difference on the structural behaviour is not distinct compare to double column. The lateral load transfer due to the separation of the beam still is intact between two free ends.

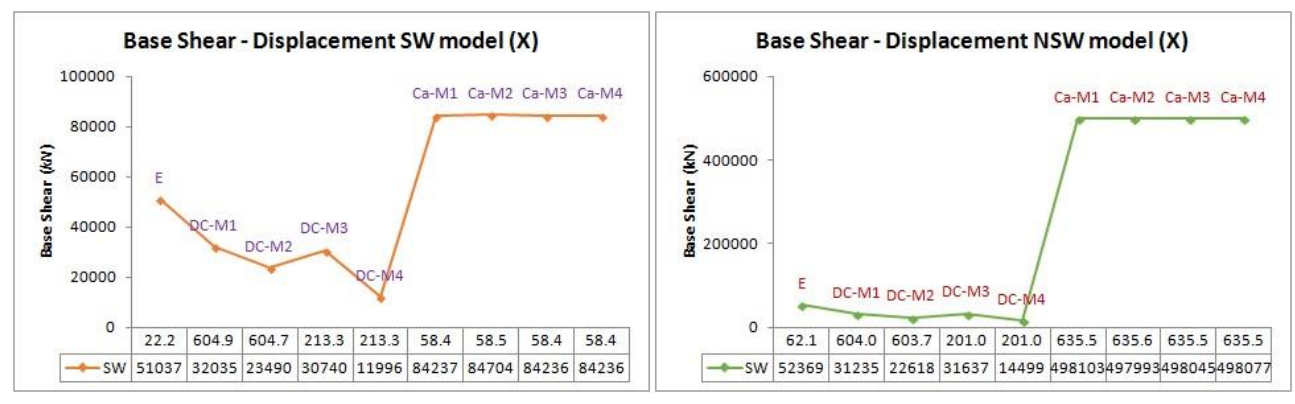

Fig. 5. Base shear - displacement relationship in the X direction for SW and NSW model

Concentrating to the displacement value respect to base shear value in the $\mathrm{X}$ direction, higher base shear produces higher displacement are consistent for DC-SW, DC-NSW, and $\mathrm{Ca}-\mathrm{SW}$; otherwise Ca-NSW does not follow the same rule. It strengthened that the presence of a shear wall will contribute substantially toward the behaviour of the building system. 
Area of shear wall covering in $Y$ direction contributes more than $X$ for the SW model. Next, the elimination of the shear wall in the cantilever beam will potentially create higher failure in the strong axis even the base shear is low.

\subsection{Displacement and drift}

Lateral drifts are the main cause of structural damage in buildings subjected to earthquake ground motions. Additionally, lateral drifts are also responsible for earthquake-induced damage to many types of non-structural elements in buildings [11]. In order to control floor stiffness, drift is more representative to be used than displacement. The displacements are measured in feet from the unstressed, un-deformed positions of the structure before the earthquake [10].
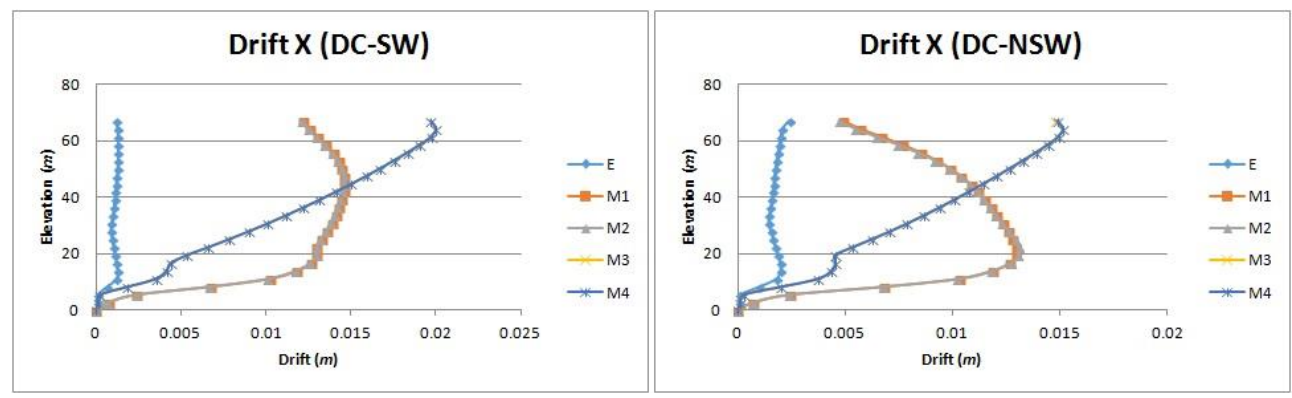

Fig. 6. Drift $X$ for double column system

Presenting drift pattern of $\mathrm{X}$ direction for both DC and Ca model in Fig. 6 and Fig. 7, it is explicit that E-SW and E-NSW result in the smallest drift whereas E-SW provides better stiffness due to shear wall presence. Disconnection of building in the $X$ direction for DC (M1 and M2) serves relatively constant drift value after $14 \mathrm{~m}$ and tends to be smaller after $56 \mathrm{~m}$ of building height. On the contrary, the drift value mounts as the building height increases except when reaching the roof floor.

Displacement value for both DC-SW and DC-NSW toward M3 and M4 however, is higher than M1 and M2. It indicates that intersecting the building in $X$ direction should be well suggested rather than $Y$. Whilst $\mathrm{Ca}$ model will perform the same as the trend as the existing for both dilatation location. Stressing for SW installation due to the choice of $\mathrm{Ca}$ model is strongly recommended (see Fig. 7).
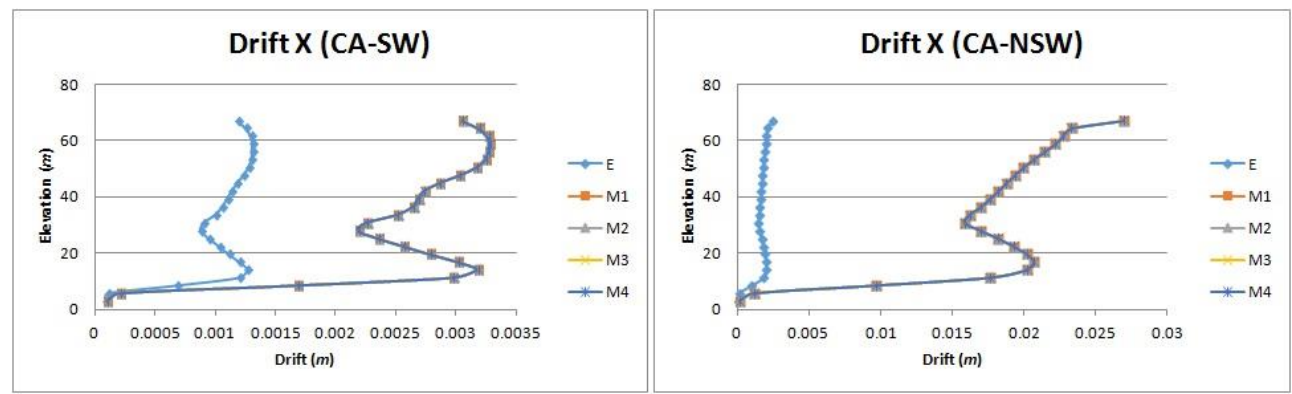

Fig. 7. Drift $Y$ for a double column system

Conform to drift and displacement discussion in $X$ direction, Fig. 8 displays $Y$ displacement results of 16 variation models. Displacement value of $Y$ direction is smaller than $X$ which proves $Y$ as the weak axis of the building. DC-M3 and DC-M4 for both SW 
and NSW indicate smaller displacement value so that it is better to separate the building in $Y$ direction rather than $X$. The same pattern is shown for the intensification of displacement value for $\mathrm{Ca}$ model in the $X$ direction as happened in $Y$-direction where the installation of shear will reinforce the building better so that the displacement can be deducted between 10 until 20 times from the NSW model. None of the direct placement of the dilatation will affect the displacement result compare to existing.

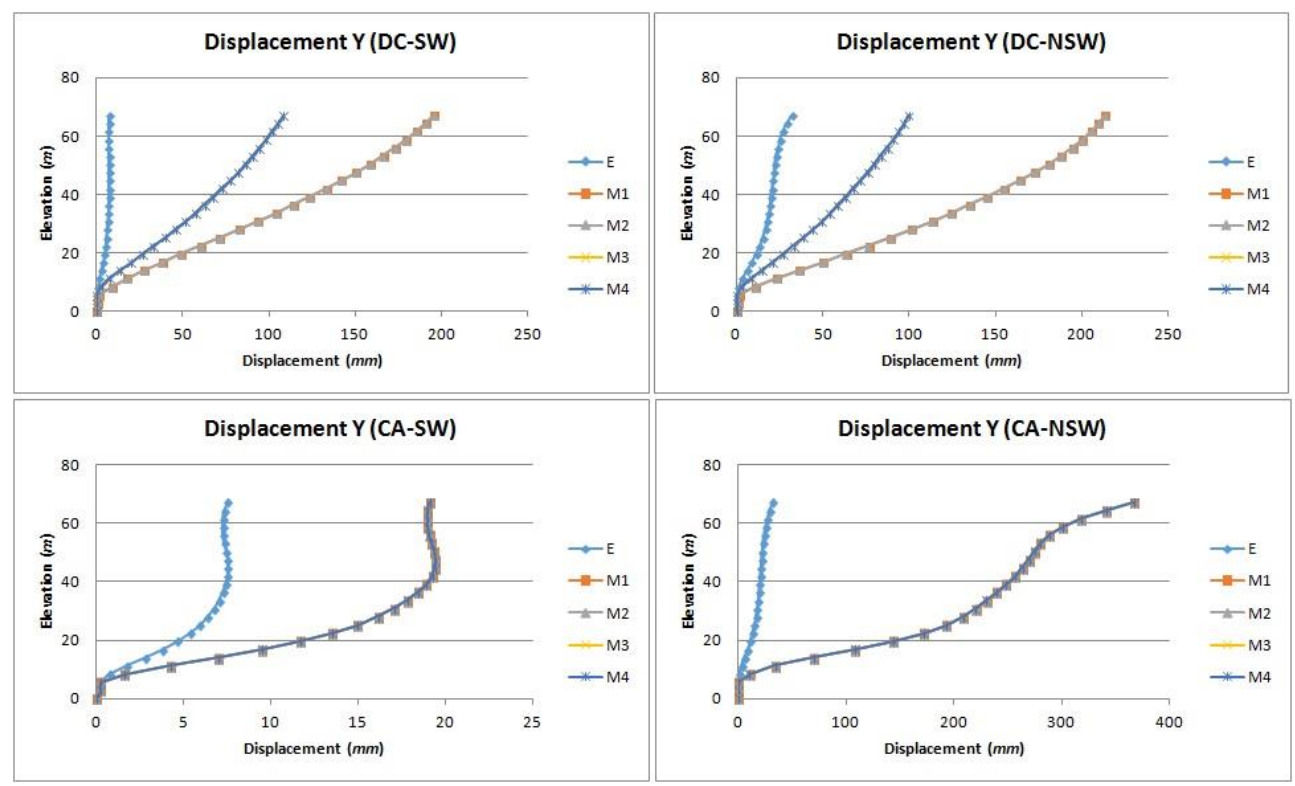

Fig. 8. Displacement $Y$ for the double column and cantilever beam system

\section{Flexure and shear performance}

Performance of the compression member denoted to column and flexure member represented by the beam are explored in this section. Performance of the column is presented using an interaction diagram below (see Fig. 9). Moment capacity is indicated in $X$-axis, other direction shows axial capacity. Column example of C89 capacity is drawn while the axial-moment capacity due to each model variation is symbolized into several dots.

Most of the variations model suffers to axial compression load rather than flexure. For the SW model, only DC-SW M1 and DC-SW-M2 which receive balance capacity for both axial and flexure. Otherwise, all Ca-NSW model experiences both axial and moment load significantly. Eliminating shear wall will lead to extra burden to the column especially when the cantilever beam is selected as dilatation choice. 


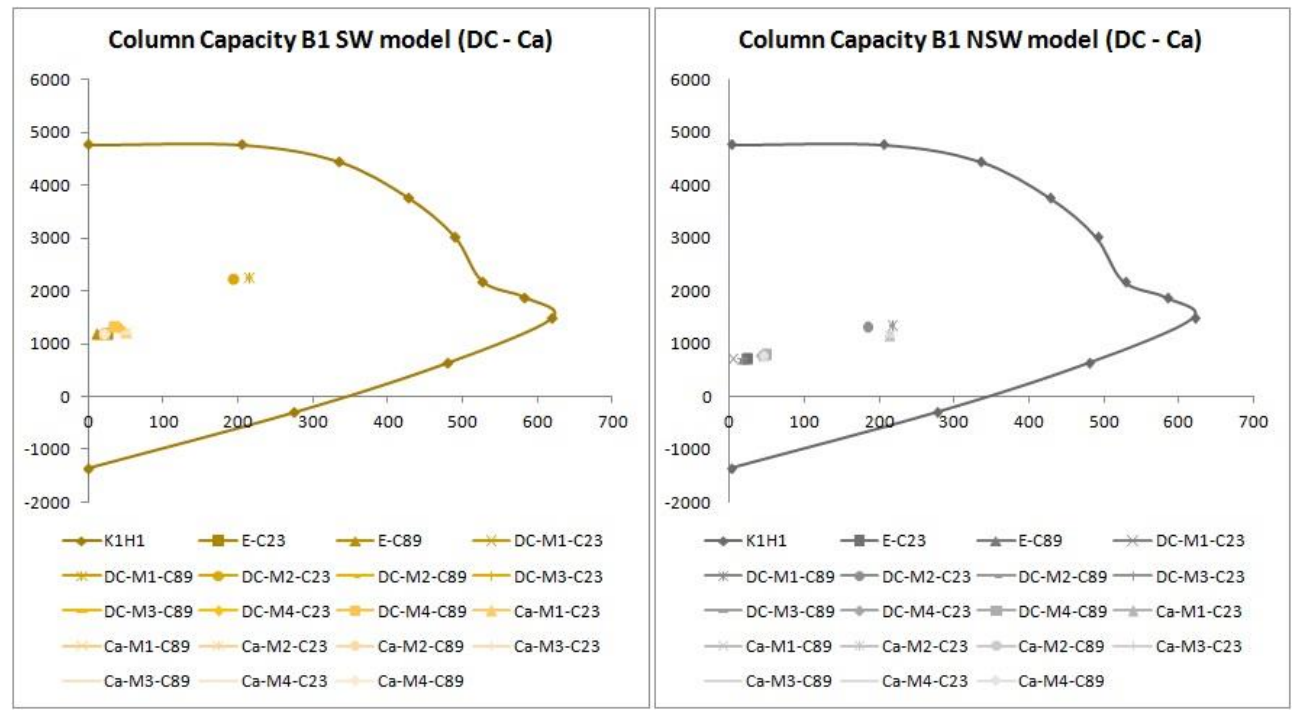

Fig. 9. Column capacity for DC and SW model (column case C89 at the basement 1)

It is proven that the column dimension and its property sufficient enough to resist the excessive load from the earthquake. Double column system will give extra resistance to the building system besides the shear wall. Cantilever beam system is notably influenced the column resistance, moreover when the shear wall is unattached.

Beam has both shear and flexure capacity under the loading. Generally, a bending moment is the main capacity which is highly concerned under transverse load started from the plastic hinge location. Shear and flexure capacity of two beam samples B88 and B90 are served in Table 4. From the existing model, shear capacity of the SW model is higher than NSW, in contrary moment capacity of the SW model is smaller than NSW.

It is well known that the shear strength of a beam is affected by the inclusion of steel reinforcements such as tension and shear reinforcements [12]. Shear capacity of DC-SW and DC-NSW is slightly the same as the existing which is also linear result with the flexure capacity results. On the other hand, $\mathrm{Ca}$ model tends to have higher shear and flexure capacity compare to existing. But, all the various models of M1 through M4 provide the same capacity values. It strengthens that $\mathrm{Ca}$ model will not be affected by the dilatation location once DC will.

Higher values of shear and flexure capacity of the $\mathrm{Ca}$ model are the outcome of the higher bending effect of the cantilever beam which influences the whole building system. Fascinatingly, Ca-SW and Ca-NSW capacity output is slightly different, where NSW model endures more load than the SW model. As the conclusion, it is aligned that shear wall will upgrade the behaviour as well as the capacity of the building system once cantilever beam is chosen for dilatation.

Table 4. Beam capacity at basement 1

\begin{tabular}{|l|c|c|c|c|}
\hline \multirow{2}{*}{ Model } & \multicolumn{2}{|c|}{ B88 } & \multicolumn{2}{c|}{ B90 } \\
\cline { 2 - 5 } & $\begin{array}{c}\text { Shear } \\
\text { Capacity } \\
(k N)\end{array}$ & $\begin{array}{c}\text { Flexure } \\
\text { capacity } \\
(k N . m)\end{array}$ & $\begin{array}{c}\text { Shear } \\
\text { Capacity } \\
(k N)\end{array}$ & $\begin{array}{c}\text { Flexure } \\
\text { capacity } \\
(k N . m)\end{array}$ \\
\hline E-SW & 43.52 & 19.48 & 34.03 & 29.64 \\
\hline DC-SW-M1 & 43.41 & 19.41 & 33.83 & 29.39 \\
\hline DC-SW-M3 & 43.10 & 19.33 & 33.33 & 28.60 \\
\hline Ca-SW-M1 & 43.66 & 19.47 & 34.19 & 29.82 \\
\hline
\end{tabular}




\begin{tabular}{|l|c|c|c|c|}
\hline Ca-SW-M3 & 43.66 & 19.47 & 34.19 & 29.82 \\
\hline E-NSW & 41.89 & 20.98 & 28.21 & 9.11 \\
\hline DC-NSW-M1 & 41.76 & 20.88 & 28.14 & 9.06 \\
\hline DC-NSW-M3 & 41.68 & 20.89 & 27.66 & 8.66 \\
\hline Ca-NSW-M1 & 43.28 & 21.87 & 28.52 & 9.44 \\
\hline Ca-NSW-M3 & 43.28 & 21.87 & 28.52 & 9.44 \\
\hline
\end{tabular}

\section{Conclusions}

Adequate numbers of variation model in this paper have directed into interesting elaboration from many aspects of the structural behaviour of the horizontally irregular building so that the best proposed dilatation between the double column and cantilever beam will be summarized below:

(a). In the needs of dilatation, the double column will perform better as the distance between the two columns is strictly close enough. Even so, the direction of intersecting the building will be better in the weak axis of the building. The shear wall will have no significant contribution after applying the double column.

(b). Cantilever beam can be considered for dilatation as the shear wall perfectly attached symmetrically inside the building plan. Shear wall is not only improving the behaviour of structure but also its capacity.

(c). It is sharply suggested to perform more experiments to get the most effective distance of double column, effective cantilever span, and shear wall configuration to the irregular building as the dilatation options.

\section{References}

1. B. S. Nasional, Tata cara perencanaan ketahanan gempa untuk struktur bangunan gedung dan non gedung. (2012).

2. V. Gioncu and F. M. Mazzolani, Earthquake Engineering for Structural Design. (2011).

3. A. Mosleh, H. Rodrigues, H. Varum, A. Costa, and A. Arêde, ISTRUC, 7, pp. 113, (2016).

4. D. Cancellara and F. De Angelis, Comput. Struct., 180, pp. 74-88, (2017).

5. B. S. Taranath, Wind and earthquake resistant buildings. (2005).

6. A. Koçak and F. Kadiog, Eng. Fail. Analy. 55, pp. 157-168, (2015).

7. F. Agamohammadzadeh, H. Afshin, and M. Nekoei, INDJST, 8, (2015).

8. Y. Bozorgnia and V. V Bertero, Earthquake Engineering - from Engineering Seismology to Performance-Based Engineering. (2006).

9. A. K. Gupta, Response Spectrum Method In Seismic Analysis and Design of Structures. (1992).

10. C. K. Erdey, Earthquake Engineering Application to Design. (2007).

11. E. Miranda and C. J. Reyes, J. Struct. Eng, 128, pp. 840-849, (2002).

12. L. Jin, X. Du, D. Li, and X. Su, Eng. Struct., 122, pp. 93-107, (2016). 